\title{
Dominus qui incepit ipse perficiat: exhortaciones de fray Josep Mercader a las monjas dominicas del monasterio de Montesión en Barcelona (1740-1745)
}

\section{Dominus qui incepit ipse perficiat. exhortations from fray Josep Mercader to the dominican nuns of the Montesión monastery in Barcelona (1740-1745)}

\author{
Alejandro José López Ribao \\ ribaotgn@yahoo.es \\ Universitat Autònoma de Barcelona
}

Instituto Histórico de la Provincia Dominicana de Aragón

\begin{abstract}
Resumen: De entre la galería de personajes interesantes que nos ofrece el convento dominicano de Santa Catalina virgen y mártir de Barcelona en el siglo XVIII destaca fray Josep Mercader (profesión 1720-1779). Un apartado importante aunque «úntimo» de su obra lo constituyen las once breves exhortaciones que entre los años 1740-1745 dirigió a las monjas dominicas del monasterio barcelonés de Montesión con ocasión de las ceremonias de recepción y profesión. En estos 20 folios podemos encontrar el discurso que un dominico cualificado dirigió a las monjas de clausura de su orden en dos momentos tan significativos de su trayectoria religiosa.
\end{abstract}

Palabras clave: Josep Mercader, dominicos (frailes y monjas), Montesión, Barcelona, sermón

\begin{abstract}
Among the many interesting people in the eighteenth century at the dominican convent of Santa Catalina virgin and martyr of Barcelona we find fray Josep Mercader (1720-1779). An important paragraph of his works, and also «private», are his eleven exhortations from 1740-1745. They are directed to the dominican nuns of the Montesión monastery in Barcelona on their ceremonies of reception and profession. In these 20 folios we find a discourse between a qualified dominican and the cloistered nuns for the occasion of the two most significant moments of their religious life.
\end{abstract}

Keywords: Josep Mercader, Dominicans (monks and nuns), Montesión, Barcelona, Sermon

\footnotetext{
* Este trabajo se inserta dentro del proyecto de investigación del Ministerio de Economía y Competitividad: «La religiosidad femenina en la Cataluña de la época moderna”, con referencia: HAR 2014-52434-C5-4-P.
} 
Alejandro José López Ribao. Dominus qui incepit ipse perficiat. exhortaciones de fray Josep Mercader a las monjas dominicas del monasterio de Montesión en Barcelona (1740-1745)

Misericordiam Dei et vestram

\section{Fray Josep Mercader: semblanza de un dominico barcelonés del Siglo de las Luces.}

De entre la amplia galería de personajes ilustres que podemos encontrar en el convento dominicano de Santa Catalina virgen y mártir de Barcelona a lo largo del siglo XVIII fray Josep Mercader (profesión 1720-1779) ha llamado nuestra atención tanto por su importante papel institucional como por su indiscutida calidad intelectual. Dicha atención se ve acrecentada por lo desconocido de su figura, ${ }^{1}$ viendo la luz sólo recientemente algún artículo dedicado a sus escritos (Grau 2012). No pretendemos en estas primeras páginas aportar una biografía exhaustiva sobre el personaje, sino simplemente delinear su trayectoria vital a través de las fechas y oficios más importantes de la misma.

Fray Josep Mercader nació en la ciudad catalana de Reus. El año 1719 entró como novicio en el convento de Santa Catalina de Barcelona, emitiendo su profesión en la sala capitular el 30 de enero de 1720 en manos del prior fray Tomás Massanes. ${ }^{2}$ En agosto de 1726 ya gozaba del grado de lector d'arts. ${ }^{3}$ Sus dotes intelectuales y organizativas debieron de ser destacadas porque en julio de 1737 fue el elegido para presidir la misa funeral por el alma de la hermana del Maestro de la Orden, e hijo del convento, fray Tomás Ripoll. Lo interesante es apreciar que el cronista lo consigna como «lo pare lector fra Joseph Mercader, agent del pare reverendíssim»>. ${ }^{4}$ Fray Tomás Ripoll, antes y después de su elección como general de los dominicos en 1725, había desplegado un importantísimo mecenazgo a favor del cenobio barcelonés; mecenazgo que se ha venido estudiando en torno a sus aportaciones librarias a la biblioteca (Ruiz 2013) pero que también benefició a la rehabilitación del edificio en su conjunto. Es comprensible que, en orden a gestionar los ingentes recursos que se hacían llegar desde Roma, el Maestro de la Orden dispusiera que un fraile, suponemos que de su entera confianza, ocupara el oficio de su agente en la comunidad, siendo J. Mercader el promocionado a dicho encargo. Tres años más tarde, en enero de 1740, es elegido prior del convento, cargo que ocupó por dos mandatos hasta febrero de $1746 .{ }^{5}$ El día 13 de febrero del mismo año es nombrado teólogo casanatense, grupo de teólogos designados por el propio Maestro de la Orden para ocuparse de los asuntos doctrinales referentes a la prestigiosa Biblioteca Casanatense, situada en el convento de Santa María sopra Minerva de Roma. Su trabajo en dicha institución duró poco, apenas cinco años, ya que por razones de enfermedad renunció en 1751, volviendo a su convento

1 Es importante destacar que su nombre no se encuentra en este exhaustivo trabajo (Collell 1965).

2 Archivo Histórico Provincia de Aragon Orden de Predicadores, ms. 31, f. 224v.

3 Biblioteca Universitat de Barcelona, ms. 1007, 332.

4 Ibidem: 337.

5 Ibidem: 338 y 352.

SCRIPTA, Revista internacional de literatura i cultura medieval i moderna, núm. 8 / desembre 2016 / pp. 314-337 ISSN: 2340-4841 · doi:10.7203/SCRIPTA.8.9302 
Alejandro José López Ribao. Dominus qui incepit ipse perficiat. exhortaciones de fray Josep Mercader a las monjas dominicas del monasterio de Montesión en Barcelona (1740-1745)

de origen (Guglielmotti 1860: 43). La actividad intelectual de fray J. Mercader no se limitó a desarrollarse ad intra de las instituciones de su orden sino que tuvo un especial repercusión fuera de ellas. Desde el 26 de mayo de 1731 fue miembro de la Academia de las Buenas Letras de Barcelona siendo nombrado en 1757 revisor de historia (Grau 2012: 280). Su actividad en la institución continuó hasta la fecha de su muerte, llevando a cabo muchos trabajos para ser leídos en sus reuniones y algunas oraciones fúnebres dedicadas a personajes importantes (Campabadal 2012: 256-257). ${ }^{6}$ Su defunción queda consignada en el libro de profesiones el día 9 de junio de 1779 a las 2 de la madrugada. ${ }^{7}$

Durante los seis años que fue prior de la comunidad de Santa Catalina (1740-1746) se ubican las once pláticas dedicadas a la recepción y profesión de las monjas del monasterio dominicano de Santa María de Montesión en Barcelona. Una de las funciones priorales era precisamente la de presidir y exhortar a las novicias en este tipo de ceremonias, recibiendo entre sus manos la profesión como queda consignado en algunas cédulas de profesión. El análisis y comentario a estas exhortaciones inéditas es el objetivo de nuestro artículo. ${ }^{8}$

\section{Descripción del material.}

La recopilación de manuscritos que nos disponemos a analizar se conserva en el CRAI Fondo de Reserva de la Universidad de Barcelona bajo la signatura «Ms. 747 Joseph Mercader O.P.: Sermones». Se compone de un total de 20 folios, en concreto de los número 31r al 40r y del 45r al 56r, en los cuales se consignan once pláticas pronunciadas en ocasión de cinco ceremonias de toma de hábito y seis de profesión en el cenobio de Montesión en Barcelona. Encontramos descrita, como nota marginal por el propio autor, la ocasión de su composición, el nombre de la religiosa, o religiosas, a quien iba destinada y el día, o días, en que se pronunció. Gracias a ello sabemos que algunas, en concreto cuatro, fueron reutilizadas en diversas ocasiones, así como las fechas de recepción y profesión de las religiosas y, en algunos casos, su proveniencia de fuera de Barcelona (Cervera o Vich) y su oficio en la comunidad (organista). Pasamos a describir los manuscritos siguiendo no el orden cronológico en que las pláticas fueron compuestas, como guardaremos en su comentario, sino el actual en que se encuentran religadas al volumen:

$6 \mathrm{El}$ único texto publicado en vida de J. Mercader es precisamente su oración fúnebre, encargada por la Academia, para el funeral del conde de Perelada en 1755 (Mercader 1756). En Archivum Generale Ordinis Praedicatorum V 13ab f. 221 se conserva una carta fechada el 9 de abril de 1756 enviada por fray Josep Mercader al Maestro de la Orden, y hermano del difunto, fray Juan Tomás de Boxadors en la cual le pide disculpas por la tardanza en ser impresa dicha oración fúnebre y le adjunta dos ejemplares de la misma.

7 AHPAOP, ms. 31, f. 224v. En el manuscrito del Archivo de la Corona de Aragón, ORM, Monacales-Universidad, volúmenes, 304, f. 22r se da noticia de que «Als 9 de juny de 1779. Als 2 quars de 3 del mati morí lo reverent pare fra Joseph Mercader. Teólac de Casanata que fou en Roma, y lo die 10 als 11 fou enterrat en lo vas dels religiosos. Requiescat in Pace. Amen〉》,.

8 Hemos encontrado un artículo similar que se ocupa de un escrito del siglo XVII (Bravo 2001). Una interpretación alegórica de la ceremonia de la profesión en (Cárdenas 2015).

SCRIPTA, Revista internacional de literatura i cultura medieval i moderna, núm. 8 / desembre 2016 / pp. 314-337 ISSN: 2340-4841 · doi:10.7203/SCRIPTA.8.9302 
Alejandro José López Ribao. Dominus qui incepit ipse perficiat. exhortaciones de fray Josep Mercader a las monjas dominicas del monasterio de Montesión en Barcelona (1740-1745)

- ff. 31r-32r inc: «Ha llegado el día en que mira cumplidas sus esperanzas...» expl: «y el de no cansar a los oyentes etcétera.» (18 de abril de 1745 para la profesión de sor Marianna Alós 9 y 8 de noviembre de 1745 para la profesión de sor Paula Vinyó $\left.{ }^{10}\right)$;

- ff. 33r-34r inc: «Satisfechos ya sus cuydados y cumplidas sus esperanzas...» expl: «ni ay razón para cansar más.» (27 de diciembre de 1741 para la profesión [sic], ${ }^{11} 8$ de diciembre de 1741 para la profesión de sor María Antonia Güell);

- ff. 35r-36r inc: «Non confundas me ab expectatione mea. Ha llegado señora al día...» expl: «tan illustre padre, son palabras de la santa etcétera.» (1740 para la profesión de sor María Teresa Alós, aunque no se indica la fecha exacta se conoce por el contexto que es el 20 de abril);

- ff. 37r-38r inc: «Consiguió la misericordia de estas señoras...» expl: «y passando a dar cumplimiento a sus deseos ha de responder etcétera.» (6 de junio de 1745 para la recepción de sor Gertrudis Arboli);

- ff. 39r-40r inc: «Suscipe me nel verbum tuum. Un año ha que la llamó Dios a su monte...» expl: «a la promesa que le haze de coronarla de gloria.» (20 de marzo de 1740 para la profesión de sor Eulalia Texidor, ${ }^{12} 20$ de abril de 1744 para la profesión de dos monjas de Vich ${ }^{13}$ );

- ff. 45r-45v inc: «Pide la mi[seri]cordia de Dios...» expl: «del Señor de ellas» (13 de junio de 1744 para la profesión de la «organista» $\left.{ }^{14}\right)$;

9 Archivo del Monasterio de Santa María de Montesión, ms. 11, f. 23v.

10 Podemos pensar que esta sor Paula Vinyó es en realidad sor Paula Frenys, que tomó el hábito un año antes y aparece con ese apellido nombrada en AMSMdM, ms. 4, f. 39r. Dicho volumen manuscrito no es un libro de profesiones sino la recopilación de juramentos ante notario que hacían las monjas antes de la profesión solemne y en los cuales alegaban que procedían libremente a la misma y sin ningún tipo de coacción. Su profesión se consigna en el AMSMdM, ms. 11, f. 24r. En este caso sí se trata de un verdadero registro de profesiones con el único inconveniente de que creemos que no quedaron consignadas todas las profesiones emitidas entre 1740 y 1743.

11 Podría tratarse de sor Escolástica Masnou y Gallicans o de Gertrudis Comadorán y Terrassa según se lee en AMSMdM, ms. 4, f. 36r. De la primera se conserva la cédula de la profesión en AMSMdM, Pergaminos de profesiones, n. 36.

12 La cédula de su profesión se conserva en AMSMdM, Pergaminos de profesiones, n. 35.

13 Las dos monjas de Vich son las hermanas María Theresa Coll y Perpiñá y Maria Anna Coll y Perpiñá como se registra en AMSMdM, ms. 4, ff. 36v-37r. La profesión quedó inscrita en AMSMdM, ms. 11, f. 23r.

14 AMSMdM, ms. 11, f. 23r. El nombre de la religiosa es sor María Catalina Font. Es muy interesante lo que se apunta en dicho libro de profesiones en ocasión de la misma para conocer la organización interna y cotidiana de la comunidad: «Als 13 de jumy 1744 ba fet profesió sor Maria Catharina Font, religiosa de obediencia y organista de adat 23 anys complert lo dia 6 de octubre 1743. Se à obligat a haver de ensenyar a totas las que dègan apèndrer y per so à resolt lo consell donar-li den de luego lo quarto de dalt de la enfermaria y quant Nostre Senyor disposia de sor Mariagna Abadal se lo donia lo que vuy abita dita sor Marianna qu és lo de baix de la emfermaria. Sols a fi de que ab tota quietut puga emplear-se en lo estudi nesesita per lo cumpliment de sa obligació. À de vestir com las demés de la obediència sens ninguna diferència ni se li à de preferir altre lloch que lo que li toquia per sa edat entra las germanas de la obediència. Sols se li ha promès no hemplear-la en obedièncias de pes com és cuinas, refator y servir las senyores de cor però pot la priora 
Alejandro José López Ribao. Dominus qui incepit ipse perficiat. exhortaciones de fray Josep Mercader a las monjas dominicas del monasterio de Montesión en Barcelona (1740-1745)

- ff. 47r-47v inc: «Conseguida la mi[seri]cordia de la religión...» expl: «a sus deseos ha de responder etcétera.» (18 de mayo de 1744 para la recepción de María Francisca Durán);

- ff. 49r-50r inc: «Conseguida la mi[seri]cordia de la religión...» expl: «ipse perficiat.» (8 de marzo de 1744 para la recepción de sor María Ignacia Guzmán, 7 de abril de 1744 para la recepción de sor Marianna Alós y 17 de noviembre de 1744 para la recepción de sor Paula Frenys);

- ff. 51r-52r inc: «Piden la mi[seri]cordia de Dios...» expl: «coronarlas de gloria etcétera.» (1 de junio de 1745 para la profesión dos monjas de Cervera $^{15}$ );

- ff. 53r-54r inc: «La misericordia pide de Dios...» expl: «en que ha de vestir y ennoblecerse su alma.» (30 de noviembre de 1740 para la recepción de sor María Antonia Güell);

- ff. 55r-56r inc: «La misericordia de Dios...» expl: «más vivas en el exe[m]plo de estas señoras.» (16 de abril 1743 para la recepción de dos monjas de Vich). ${ }^{16}$

\section{El contexto litúrgico como elemento explicativo de la composición.}

Una cuestión que ayuda a entender los escritos referidos es la concerniente a su género literario: ¿son sermones vinculados a una celebración solemne litúrgica, especialmente eucarística, como se podría desprender del título general que rige el volumen donde están inseridos?, ¿`son pláticas como el inventario de manuscritos de la biblioteca nos las presenta? (Miquel 1958: 274-275) y, en ese caso, ¿qué relación guardaban con la ceremonia en sí misma y dónde se localizaban en relación a su ordo? La pregunta puede parecer menor pero su respuesta nos proporciona la justa medida de su comprensión e importancia.

En primer lugar queremos negar que se traten de sermones en su acepción conveniente de prédicas solemnes. Para cualquier persona avezada en la predicación barroca será fácil echar en falta los elementos característicos de la misma. Su corta extensión (no pasan de dos o tres páginas todos ellos), la falta de un thema como cita bíblica programática en la mayoría de casos, su falta de estructuración externa e interna conforme a los cánones de la gran predicación y su brevedad en la exposición temática nos hacen llegar a esta conclusión. T. Egido afirma que, en lo que concierne a la estructura del sermón, no se consiga en el siglo XVIII ninguna novedad, siendo que «exordio para captar la benevolencia y la atención, narración, información y conclusión son los integrantes

emplear-la en lo que sia menester com no se oposia ni la impedesca de la prinsipal obligació com és asistir a las malaltas los ratos puga cosas semblans, y ab estas condicions se és admesa a la profesió» (ff. 23r-23v). Su cédula de profesión se conserva en AMSMdM, Pergaminos de profesiones, n. 37.

15 El volumen AMSMdM, ms. 4, f. 38v indica que los nombres son sor María Gertrudis Moxó y Mareñosa y sor María Antonia Moxó y Mareñosa; AMSMdM, ms. 11, f. 23v.

16 Vide nota 16.

SCRIPTA, Revista internacional de literatura i cultura medieval i moderna, núm. 8 / desembre 2016 / pp. 314-337 ISSN: 2340-4841 · doi:10.7203/SCRIPTA.8.9302 
Alejandro José López Ribao. Dominus qui incepit ipse perficiat. exhortaciones de fray Josep Mercader a las monjas dominicas del monasterio de Montesión en Barcelona (1740-1745)

de la oración, que debe seguir las exigencias del arte en su uso y en la invención de las verdades, en la recta disposición y elocuencia del discurso» (1996: 774) y ninguna de estas partes se adivinan en nuestros escritos. Sin duda el nombre de «pláticas con motivo de» (Miquel 1958: 274) que nos ofrece el inventario de la biblioteca es más apropiado, aunque por su propia definición genérica de discurso doctrinal es poco precisa y sobre todo poco descriptiva del contexto celebrativo.

La edición de la regla y constituciones por las que se debieron regir estas ceremonias es la correspondiente a la del Maestro de la Orden fray A. Cloche (1628-1720) elegido por el capítulo general de Roma en 1686. Dichas constituciones se editaron en Roma el año 1690 y en ellas, como era costumbre en la época, se legislaba tanto para los frailes como para las monjas y los terciarios. En el capítulo XIV De recipiendis se apunta:

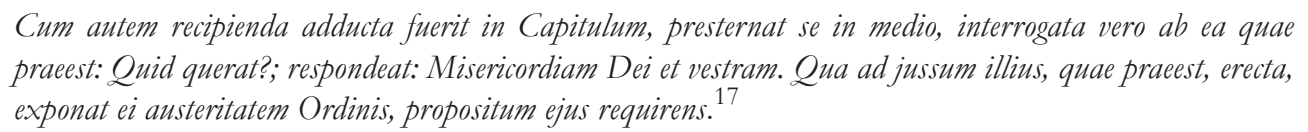

De igual forma en el capítulo XVI De modo faciendi professionem indica:

\footnotetext{
Modus faciendi professionem talis est: ego soror $N$. facio professionem, et promitto obedientiam Deo, (...) usque ad mortem. Novitiarum autem vestes in earum professione benedicantur hoc modo: V/ Ostende nobis Domine misericordiam tuam. R/ Et salutare tuum da nobis; V/ Domie exaudi orationem meam, R/ Et clamor meus ad te veniat; Oremus. ${ }^{18}$
}

Aunque sin duda nos ayudará más a nuestro fin el texto descrito en el Formularium en su apartado Forma et modus faciendi professionem:

\footnotetext{
Completo anno Magister Novitiorum ducat novitium in capitulum ante priorem et facta prostratione, et petita misericordia Dei, et Ordinis, et expositis ei per priorem impedimentis et austeritatibus ut supra in receptione novitii notatum est, et novitio promittente se illas servare velle, prior dicat: Dominus, qui incepit ipse preficiat, et conventus respondeat Amen (...). Postea solus prior recipit ipsum ad osculum pacis. Completa professione, prior benedicat scapulare. ${ }^{19}$
}

17 Regula S. Augustini et Constitutiones ff. ordinis praedicatorum nunc recenter reimpressae. Jussus reverendiss. patris Antonini Cloche, ejusdem Ordinis Magistri Generlis, Roma, Typis Nicolai Angeli Tinassii, 1690, 13.

18 Ibidem: 15-16.

19 Ibidem: 303. 
Alejandro José López Ribao. Dominus qui incepit ipse perficiat. exhortaciones de fray Josep Mercader a las monjas dominicas del monasterio de Montesión en Barcelona (1740-1745)

Hemos querido reproducir estos tres textos para constatar las siguientes observaciones. En primer lugar dejan claro que la celebración no se inserta en un contexto eucarístico sino capitular (adducta fuerit in Capitulum) lo que explica la nula existencia de citas textuales, y una única sucinta cita formal, a textos pertenecientes a la liturgia eucarística (como el Introito, la Epístola o el Evangelio) en nuestros textos; menciones que normalmente son usuales en sermones relacionados con dicho contexto.

En segundo lugar se nos indica que, tras la fórmula «Misericordiam Dei et vestram», a la orden de quien preside, la candidata se levanta y se le exponen las austeridades de la orden, preguntándosele finalmente por su propósito (Qua ad jussum illius, quae praeest, erecta, exponat ei austeritatem Ordinis, propositum ejus requirens). Esta exposición de las austeritatem ordinis, esta exhortación en definitiva a ser consciente del acto que está llevando a cabo, de lo que significa la vida en religión y de lo que supone, la lleva a cabo quien preside la ceremonia (el prior de Santa Catalina en nuestro caso) y es importante notar que es el único momento de «intervención libre» del presidente que prevén las constituciones.

En tercer lugar destacamos la fórmula prevista en orden a ser pronunciada por la novicia o profesa en la recepción y profesión: «Misericordiam Dei et vestram». Dicha fórmula es exclusiva del contexto litúrgico que estamos analizando, al no ser extraída de ningún texto bíblico ni oración o responsorio; y precisamente es la frase más glosada y repetida en nuestros textos. Siete de las once pláticas, tanto de recepción como de profesión, la enuncian en sus primeras palabras y en la mayoría de éstas se repite como un leitmotiv a lo largo de su corta extensión, articulándola y centrando el tema. La última fórmula ritual que podemos nombrar es «Dominus qui incepit ipse perficiat», recitada tras la aceptación de la candidata a la exhortación previa y que de igual forma se hace presente, de forma textual, como palabras finales de uno de los escritos.

Tras lo que hemos expuesto podemos afirmar que el contexto comprensivo de estos escritos es la ceremonia de la vestición del hábito o la profesión y que sus referencias textuales y temáticas los relacionan claramente al momento en que el presidente debía exhortar a la candidata antes de recibir su aceptación final. Por ello nos encontramos ante unas composiciones breves pero significativas del discurso de los religiosos dominicos sobre las monjas de la misma orden, ya que aunque sean sucintas sus palabras son previstas en un ambiente de profunda escucha y recuerdo religioso. Es en este punto donde creemos que reside su importancia y su mayor valor.

¿Seguían las monjas dominicas españolas alguna peculiaridad en la ceremonia de su profesión? La pregunta no es irrelevante y la respuesta parece ser afirmativa. Esta peculiaridad sería el uso de recitar tras la fórmula de la profesión y antes de la bendición del escapulario el versículo 116 del salmo 118: «Suscipe me secundum eloquium tuum, et vivam, et non confundas me ab expectatione mea». La proclamación de este versículo relacionaría a las monjas españolas con aquellas órdenes que siguen la regla benedictina, ya que en ella se contempla dicho uso en el capítulo LVIII De disciplina suscipiendorum fratrum: "Quam dum inposuerit incipiat ipse novicius mox bunc versum: Suscipe me secundum eloquium tuum, et vivam, et non confundas me ab expectatione mea. Quem versum omnis congregatio tertio respondeat, adiungentes gloria Patrì (Benet de Nursia 1997: 240). 
Alejandro José López Ribao. Dominus qui incepit ipse perficiat. exhortaciones de fray Josep Mercader a las monjas dominicas del monasterio de Montesión en Barcelona (1740-1745)

Nos lleva a plantear esta hipótesis el hecho de que en dos de las exhortaciones para la profesión nuestro dominico utiliza dicho versículo como thema, reservándose normalmente para esta cita programática alguna significativa del contexto litúrgico o temático. En la traducción a lengua vernácula de las constituciones publicada en 1826 como Regla de San Agustín y Constituciones que profesan las religiosas del Patriarca Santo Domingo, se indica «acabada de hacer la profesión, inmediatamente ha de decir «Suscipe me secundum eloquium tuum et vivan et non confundas me ab expectatione mear, ${ }^{20}$ mientras que en otras ediciones anteriores en lengua italiana no se contempla este añadido como es el caso Regola e costituzioni delle suore di san Domenico reviste e ristampate d'ordine del reverendissimo padre Generale fra Antonino Cloche, publicada en Roma el año $1709 .{ }^{21}$ Por último, en un largo y pormenorizado comentario (768 páginas) a la regla y constituciones dedicado a sor G.M. Vittoria Doria Landi escrito por fray P. Ricchiedei no se encuentra nada relativo a este salmo en la exhaustiva explicación que hace de todos los elementos de la profesión (Ricchiedei 1710: 500-521). La omisión de este detalle en las ediciones italianas y su constatación en las españolas así como su presencia en nuestros textos nos llevan a pensar la existencia distintiva de este detalle monástico benedictino en la profesión de las monjas dominicas españolas.

\section{Fuentes utilizadas por Josep Mercader en la composición de las pláticas.}

En la elaboración de sus exhortaciones fray J. Mercader usa cinco tipos de fuentes: bíblicas, litúrgicas, teológicas, hagiográficas y otros sermones o pláticas publicadas.

El uso recurrente de citas bíblicas, tanto de forma textual en latín como formal en castellano o articulando pequeños discursos intercalándolas, es uno de los recursos retóricos más importantes del texto. Por ello la Biblia se distingue como la fuente principal del mismo. Las citas más numerosas son las extraídas del corpus veterotestamentario, destacando especialmente el libro de los Salmos. En concreto son citas textuales de éste las siguientes: Ps 102, 4 (ff. 50r y 39r); Ps 118, 116 (ff. 39r, 35r y 35v); Ps 49, 14 (ff. 40r, 52r); Ps 44, 10-11 (f. 35r); Ps 65, 13 (f. 35v) y Ps 88, 2 (f. 45r). En cuanto al resto de libros del Antiguo Testamento el uso de citaciones textuales y formales es menor. Del libro del Génesis encontramos sólo una cita textual Gen 19, 19 (f. 37v). Del Éxodo destaca una cita formal sobre la columna de fuego que guió a Israel por el Mar Rojo de Ex 13, 21-11 (f. 55r). El Cantar de los Cantares sólo aporta la cita textual Cant 5, 1 (f. 39r) y del Eclesiastés se reproduce textualmente la necesaria cita para la ocasión «Transeunt universa sub sole» de Eccl 3, 1 (f. 39r). Por lo que respecta al libro de los Proverbios se encuentra textualmente citado Prov 4, 11-12 (ff. 33v y $31 \mathrm{v}$ ) y por último los escritos proféticos sólo se mencionan a través de la cita textual de Is 61, 10 (f. $53 \mathrm{v})$. Mucho menores son las citas textuales del Nuevo Testamento ya que sólo descubrimos la de Ioan 3, 29 (f. 35) y Lc 10, 28 (f. 45r).

20 Regla de San Agustin y Constituciones que profesan las religiosas del Patriarca Santo Domingo, Vitoria, Agapito Manteli, $1826,88$.

21 Regola e costituzioni delle suore di san Domenico reviste e ristampate d'ordine del reverendissimo padre Generale fra Antonino Cloche, Roma, Francesco Gonzaga nella Stamperia del Tinassi, 1709, 54-55. 
Alejandro José López Ribao. Dominus qui incepit ipse perficiat. exhortaciones de fray Josep Mercader a las monjas dominicas del monasterio de Montesión en Barcelona (1740-1745)

De entre las citas del Nuevo Testamento enunciadas a nivel formal sobresale, de forma lógica, la continua mención a las vírgenes prudentes de Mt 25, 1 (ff. 49r, 47r y 33v) y, debido a la sobresaliente relación que se establece entre la estrella vista en la frente de santo Domingo y la que guió a los magos, Mt 2, 1-12 (ff. 49r, 47r, 37r y 51r). También se menciona el pasaje que recuerda a la Virgen María en Montesión de Ioan 19, 25 (f. 49v), un uso esporádico de Hechos en Act 2, 3 (f. 37r), la perícopa introductoria a la parábola del Buen Samaritano en Lc 10, 25-31 (f. 45r) y, por último, se recuerda una de las apariciones del Resucitado del mismo evangelio de Lc 24, 36 (f. 56r). Una composición interesante por su capacidad retórica, al permitir citar el nombre e ideal contemplativo del monasterio, es la que combina las citas formales de Apoc 14, 1, Apoc 14, 4 y Mt 25,1-13 resultando la evocación del Cordero que vio san Juan en Montesión a quien siguen las prudentes vírgenes. El poder evocador es claro y por ello es una de las citaciones más usadas (ff. 55v, 49v, 47v y 37r, 51v).

Otra forma de trabajar las fuentes escriturísticas a nivel retórico es recurrir a la historia sagrada por su valor ejemplificante. Este es el caso del libro de Esther en el capítulo segundo (f. 55v) y de la historia de Lot y su mujer de Gen 19, 15-29 (ff. 47v y 37v).

El segundo tipo de fuentes usadas son las litúrgicas. Dentro de ellas podríamos integrar las mencionadas anteriormente relativas al ceremonial de recepción y profesión con las fórmulas de petición de misericordia (Misericordiam Dei et vestram), de conclusión del rito (Dominus qui incepit ipse perficiat) y la proclamación del versículo del salmo 118 por parte de la profesa (Suscipe me secundum eloquium tuum, et vivam, et non confundas me ab expectatione mea). Debido a que ya han sido tratadas con profundidad anteriormente no las volveremos a mencionar en este apartado y dedicaremos nuestra atención a las provenientes del oficio divino y el calendario. Las lectio de los nocturnos constituyen un material reconocible y cotidiano para la mentalidad del auditorio conventual y por ello el predicador no duda en utilizarlo. Es el caso de dos de los pasajes dedicados a exhortar a las candidatas a través de ejemplos de las santas mujeres. El primero se refiere a la conversación entre santa Águeda y Quintiniano que J. Mercader menciona en dos ocasiones (ff. $53 \mathrm{r}$ y $55 \mathrm{v}$ ) y que se lee en la lectio IV del nocturno II del día de su fiesta. ${ }^{22}$ El otro se refiere al episodio sucedido cuando santa Catalina de Siena visita el cuerpo de santa Inés de Montepulciano (f. 36r) constituyendo la lectio III del nocturno proclamado en el oficio coral el día de su memoria. Aunque esta cita podría vincularse sin duda a diversas biografías de santa Catalina nos parece la recogida en el oficio la más ajustada al discurso que el autor desarrolla, ya que recoge la idea de paridad entre las dos santas y el hecho de que la santa de Montepulciano fue un arquetipo de la santa de Siena. ${ }^{23}$ Otro uso del oficio divino es el de la antífona «Virgo gloriosa semper evangelium Christi gerebat in pectore et non diebus neque noctibus a colloquiis divinis et oratione cessabat» correspondiente a las primeras vísperas de la fiesta de santa Cecilia (f. $45 \mathrm{v}){ }^{24}$

22 Breviarium Sacri Ordinis Praedicatorum auctoritate apostolica approbatum et reverendissimi P. F. Thomae Ripoll ejusdem Ordinis Generalis Magistri Jussu editum, Roma, Typis Hyeronimi Mainardi apud theatrum Capranicense, 1738, 533.

23 Ibidem: 593.

24 Ibidem: 831.

SCRIPTA, Revista internacional de literatura i cultura medieval i moderna, núm. 8 / desembre 2016 / pp. 314-337 ISSN: 2340-4841 · doi:10.7203/SCRIPTA.8.9302 
Alejandro José López Ribao. Dominus qui incepit ipse perficiat. exhortaciones de fray Josep Mercader a las monjas dominicas del monasterio de Montesión en Barcelona (1740-1745)

Cuando indicamos el calendario como fuente temática de las exhortaciones queremos manifestar que su composición y alocución en un día concreto del calendario litúrgico condiciona y aporta explicación sobre su contenido. Es el caso de la mención a santa Inés de Montepulciano (f. 36r) que encuentra su razón de ser en que sor María Teresa Alós profesa el día de su fiesta, el 20 de abril; y de igual forma sucede con la dedicada a san Andrés (f. 54r) en la toma de hábito de son María Antonia Güell el 30 de noviembre. El 20 de abril podía ser una ocasión propicia para la profesión de las religiosas dominicas ya que en él también emitieron sus votos otras monjas en 1744 (f. 39r). Pero no sólo el santoral ejerce su influencia sobre las pláticas sino también los diversos ciclos litúrgicos. Éste es el caso señalado en la recepción de dos monjas el 16 de abril de 1743. La pascua ese año se celebró el 14 de abril siendo así que era la feria tertia de la Semana de Pascua en la cual se leía como evangelio de la misa Lc. 24, $36^{25}$ lectura que explica la única mención temática a la paz que ofrece Cristo a las que abrazan el estado religioso (f. 56r).

La hagiografía es sin duda una de las disciplinas que con más facilidad puede nutrir la retórica sagrada y especialmente en el caso de nuestros textos, en los que se recuerda a las candidatas que la forma de alcanzar la santidad es imitando los buenos caminos de sus santas predecesoras en la orden. La literatura hagiográfica y todas sus derivaciones, como su uso en pláticas o sermones, tuvo un papel importante en el proceso de disciplinamiento «en la medida en que se orientaba a modelar comportamientos, y fue expresión y exponente participante al mismo tiempo del proceso de confesionalización» (Atienza 2013: 93-94). Sin embargo, en las pláticas estudiadas no se nos ofrece una retórica hagiográfica profusa sino que solamente se tratan de forma desarrollada algunos episodios de la vida de santa Catalina de Siena. Al ser genéricas sus alusiones es difícil situar la fuente que utilizó J. Mercader para su consulta, pero parece claro que debió ser en alguna de las populares biografías de la santa que se publicaron aquellos años. Es el caso de la del dominico castellano fray S. García Admirable y prodigiosa vida de la seráfica y esclarecida virgen santa Catalina de Sena de la Tercera Orden de Penitencia que fundó santo Domingo, inclito patriarca de la religión ilustre de Predicadores en 1729 y de la de fray Ll. Gisbert i Caspir, fraile valenciano de la misma orden, titulada Portentosa vida de la seráfica madre y cándida virgen santa Catalina de Sena publicada en 1690.

Continuando con otras fuentes impresas la más destacada es el Prontuorio de J. Medina (1705). En dicha obra el fraile menor observante ofrece, preparadas para su predicación, pláticas y exhortaciones para todo tipo de situaciones que pudiese encontrar un superior. Y como no podría ser de otra manera entre ellas se cuentan tres pláticas «Para dar el hábito a monja»y otras tres «Para la profesión de monja» (1705: 383-421). El uso que hace nuestro dominico de ellas es extenso, siendo que en algunas de sus exhortaciones sigue el desarrollo de las ideas ofrecidas o copia textualmente dicho manual.

25 Missale sacri ordinis praedicatorum. Auctoritate Apostolica approbatum Rmi. P.F. Thomae Ripoll eiusdem ordinis generalis magistri iussu editum, Roma, Typis Hyeronimi Mainardi apud theatrum Capranicense, 1726, 229.

SCRIPTA, Revista internacional de literatura i cultura medieval i moderna, núm. 8 / desembre 2016 / pp. 314-337 ISSN: 2340-4841 · doi:10.7203/SCRIPTA.8.9302 
Alejandro José López Ribao. Dominus qui incepit ipse perficiat. exhortaciones de fray Josep Mercader a las monjas dominicas del monasterio de Montesión en Barcelona (1740-1745)

La última de las fuentes que podemos citar son los escritos teológicos. Ésta es sin embargo la más difícil de precisar, ya que en la mayoría de casos se reducen a citas breves y descontextualizadas, muchas de ellas formales, de diversos autores sin indicar su procedencia. Explicación de esta «forma precaria» en la citación puede ser que nos encontramos ante unos manuscritos no pensados para su publicación sino tan sólo para su utilización inmediata en las ceremonias correspondientes. No son simples apuntes temáticos pero tampoco textos finales para ser llevados a la imprenta. A ello se debe unir que, no en pocos casos, fueron extraídas directamente del volumen de J. Medina antes mencionado, sin consultar el autor las obras originales en que podrían estar contenidas. Una tendencia sería la voluntad de introducir en el discurso a teólogos dominicanos, como es el caso del cardenal Hugo de San Caro (f. 39r) o de fray Luis de Granada (f. 39v), así como la significativa falta de citas a obras de santo Tomás de Aquino, prototipo de teólogo en su orden. También hay referencias a autores franciscanos como san Bernardino de Siena (f. 39v), a preclaros ejemplos de la patrística oriental, san Gregorio Nacianceno (f. 53r), y occidental, san Ambrosio de Milán (f. 53r) y a representantes del temprano monacato como Casiodoro (f. 35v). Una especial consideración merece san Bernardo (ff. 35r, 33r y 31r) y su sentencia «amor conciliat professio maritat» que parece ser la más adecuada para el orador a la hora de explicar qué añade la profesión religiosa a la vestición del hábito. ${ }^{26}$

\section{Audi filia: el material temática de las pláticas}

Intentar explicar lo que la predicación y el predicador suponían para la sociedad del Antiguo Régimen es una empresa poco menos que imposible (Egido 1996: 761). Lo es en parte por la ascendencia que tuvo sobre las mentalidades colectivas de su auditorio y las ocasiones ceremonialmente repetidas que contaba para dirigirse a él (Esponera 1997: 365-367), en parte por el volumen que ocupó la predicación en la producción editorial (Aguilar 1989: 54) y asimismo porque la masa enorme de composiciones de este tipo que nos han llegado no es sino una parte mínima de lo que se predicó en ese siglo que

\footnotetext{
al no haber sido empeño de personajes ilustres, al no haber encontrado financiadores (esos mecenas numerosos y vanidosos que sufragan la impresión) ni estímulos de propaganda u otros alicientes, como el de servir de sermonarios para inspirar a otros predicadores menos dotados, no pasaron del púlpito de la palabra al escrito de la imprenta (Egido 1996: 761).
}

El fino espíritu ilustrado no podía, por todo ello, ser ajeno a la importancia e influencia que la predicación ejercía sobre la población, de la misma manera que no podía dejar de criticar los excesos barrocos de la misma. Por ello no nos puede extrañar que una de sus preocupaciones fuera la reforma de la oratoria sagrada. Ilustrados tan relevantes como G. Mayans, J. Climent, que llegaría

26 Dicha cita esta extraída del Sermón LXXXV In cantica (Clarae-Vallensis 1839: 3193). 
Alejandro José López Ribao. Dominus qui incepit ipse perficiat. exhortaciones de fray Josep Mercader a las monjas dominicas del monasterio de Montesión en Barcelona (1740-1745)

a ser obispo de Barcelona entre los años 1766-1775 y bien relacionado con el convento de Santa Catalina de Barcelona, F. Bolifón, F. Bertrán o L. Soler de Cornellá no cejaron en este empeño en la década sucesiva a la composición de las pláticas que ahora nos ocupan. ${ }^{27}$

A la hora de llevar a cabo el análisis y exposición argumentativa de las onces pláticas hemos de tener en cuenta que muchos de los temas presentes en ellas son comunes. El hecho se debe a que en bastantes ocasiones se utiliza el mismo esquema conceptual e incluso las mismas expresiones en varias de ellas, especialmente en el caso de las exhortaciones pronunciadas en iguales circunstancias, siendo así que el corpus temático es reducido. Sin embargo, existen particularidades y matices interesantes, así como algunos argumentos que son desarrollados por especificidades coyunturales que tuvo en cuenta el predicador a la hora de construir su discurso. Para presentar todo ello hemos decidido comentar por separado los escritos dedicados a la vestición y a la profesión, exponiendo a continuación los temas ocasionales que aparecen en ellos acompañados de su justificación. Por último, hemos querido dedicar un momento concreto a los exempla femeninos que son presentados a las religiosas por su significado especial dentro de la configuración de la religiosidad femenina del momento.

Las cinco pláticas para la vestición del hábito comienzan retomando la fórmula rogativa de misericordia: «conseguida la misericordia de la religión pide ansiosa la misericordia de Dios por cuyo fin desea en este real monasterio vestir el hábito de mi padre santo Domingo». ${ }^{28}$ Esta resolución se contempla como nacida en la ternura de los deseos y ya por fin robustecida, gracias a la reflexión, pasa ese día desde del corazón a los labios para ser proferida, edificando a cuantos la escuchan. ${ }^{29}$ Son muy poco comunes las menciones a las circunstancias particulares de las candidatas, su recorrido en el monasterio o la existencia de público al acto religioso. Sin embargo, puntuales detalles nos indican que algunas de ellas debieron ser educadas en el mismo o pasaron en él largas temporadas antes de ingresar, así como que sus familiares estarían presentes en la función religiosa. Al respecto se nos recuerda que

En efecto, sabemos que en los cenobios femeninos podían estar también simples mujeres que buscaban un cobijo, un retiro espiritual al final de sus días, aun su propia rehabilitación social, y, por supuesto, niñas y jovencitas que, sometidas a estrictas reglas de vida, crianza y educación en aquéllos se convertían en «aprendices de futuras monjas (Gómez 2011: 216).

27 Ilustrador de ello es (Mestre 1997: 245-263). También del mismo autor para entender qué significaba la propugnada «renovación de la predicación” se puede consultar (Mestre 1979: 88-119).

28 BUB, ms. 747, f. 47r. Para la transcripción de fragmentos del manuscrito que presentamos en nuestro artículo hemos decidido respetar la ortografía original aunque acentuando y puntuando según la normativa actual en orden a facilitar la lectura.

29 Cf. Ibidem: f. 49r. 


\section{Alejandro José López Ribao. Dominus qui incepit ipse perficiat: exhortaciones de fray Josep Mercader a las}

monjas dominicas del monasterio de Montesión en Barcelona (1740-1745)

Sólo así podemos entender expresiones como: «ha illuminado sus passos a esta religiosa casa en donde ha tenido mucha parte su educación honesta» ${ }^{30} \mathrm{o}$ «avía ya gustado las seguridades que dexan hallarse en el retiro de un claustro y después de aver examinado discreta que era del esposo el clamor que se oía, sollicita oy ha entrado como hizieren allá las vírgenes prudentes» ${ }^{31} \mathrm{y}$ 《a quanto podía darle el mundo, lisonjeando su appetito, tiempo ha señora que tenía cerrada la puerta pero oy arroja generosamente la llave sin reservarse libertad de poder recobrarla». ${ }^{32}$ Por lo que se refiere a la asistencia de más «público» que el predicador y las monjas se deja vislumbrar en pasajes como «miro con respeto a los que han concurrido a esta función religiosa y tierna, porque a la luz de la lámpara (...) dexa mirarse más respetuoso el motivo de sus asistencia». ${ }^{33}$

Uno de los grandes temas conductivos de las pláticas es el motivo de la luz. Ésta se valora como fuente de iluminación, calor, guía y a su vez constituye una clara mención a la figura del santo fundador de la religión siguiendo las descripciones de sus coetáneos que afirmaban constatar una fuerte luz o estrella en su frente (Gómez 2011: 208). Es, en última instancia, metáfora de la vocación religiosa y hace de auténtico vehículo a la idea de la misma. La vocación, en palabras de J. Mercader, nace del desengaño temprano y pasa del conocimiento a la voluntad para avivar los afectos:

Dexó verse en su alma la luz del desengaño en la tierna edad que la aparta del peligro, y passando desde su conocimiento a la voluntad esta luz ha proseguido en calentar sus affectos sin castigarse entre los ayres del siglo ni resfriarse entre los soplos del ahogo. Esta es la luz de la vocación religiosa que suele encender Dios en las almas. Esta la estrella de mi santo patriarca, que brillando desde su frente con toda la luz que illumina a su orden, dexó verse en lo interior de su pecho, que dirigida y encaminada a su casa como hizo aquella otra guiando a los reyes. ${ }^{34}$

Seguir esta luz, impresa en la regla y las constituciones, será la forma clara de discernir los caminos adecuados a la vocación y así llegar a la rogada misericordia de Dios y la santidad: «son diferentes los caminos y diferentes las mansiones que tiene Dios en su casa y para acertar el de la mi[seri]cordia que pide (es) norte seguro poner la vista en aquella luz misma que oy la llama para entrar en esta casa». ${ }^{35}$

Otro tema importante es el de la libertad. Éste se contempla en dos aspectos concretos: la afirmación de que la verdadera libertad consiste en cumplir la voluntad de Dios y vivir consagrada a su servicio, y el recuerdo, constante en todas las exhortaciones, de que las candidatas deben actuar con plena

30 BUB, ms. 747, f. 53r.

31 Ibidem: f. 49r.

32 Ibidem: f. 53r; igual expresión se usa en f. 49r.

33 Ibidem: f. 53 r.

34 Ibidem: f. 47r.

35 Ibidem: ff. $37 \mathrm{r}-37 \mathrm{v}$

SCRIPTA, Revista internacional de literatura i cultura medieval i moderna, núm. 8 / desembre 2016 / pp. 314-337 ISSN: 2340-4841 · doi:10.7203/SCRIPTA.8.9302 
Alejandro José López Ribao. Dominus qui incepit ipse perficiat. exhortaciones de fray Josep Mercader a las monjas dominicas del monasterio de Montesión en Barcelona (1740-1745)

libertad a la hora de escoger el camino de la clausura. La religiosa, tras su entrada en el monasterio, «desposeída toda de su alvedrio busca en Dios la libertad de la gracia en cuya vida respiran con Dios sus esposas». ${ }^{36}$ Ilustración de esta verdadera libertad que nace del sólo servir a Cristo y no al mundo, y en especial a los poderosos, son las palabras de santa Águeda a Quintiniano: «con singular energía dixo a Quintiniano santa Agatha que la libertad verdadera y la mayor nobleza ha de buscar en la estrecha unión con Jesucristo» y lo corrobora las sentencias de san Gregorio Nacianceno y san Ambrosio de Milán que esgrime el orador, recordando que el primero «reduce toda la nobleza y fortuna del siglo a una necessitud y coherencia firme con Dios» ${ }^{37}$ y el segundo «porque como discurre san Ambrosio si es dignidad y honrosa distinción de los grandes servir a la persona de un monarca quanto mayor deve estimarse la de servir al Rey de los Cielos y elevarse por su gracia a ser hija, esposa del Rey de los Reyes». ${ }^{38}$

La necesidad de ser completamente libre a la hora de decidir entrar en religión es uno de los leitmotiv de las exhortaciones. La atracción de los investigadores por conocer las motivaciones que llevaban a profesar la vida religiosa ha sido grande y sus respuestas variadas, desde una cierta búsqueda de libertad personal hasta una sincera vocación contextualizada en una sociedad fuertemente sacralizada. En todo ello podía contar un papel destacado la tratadística de la época que aconsejaba la persuasión pero no la constricción a la hora de entrar en religión (Gómez 2011: 218). La continua mención que podemos leer a que «nadie la obliga a tomar el estado de religiosa pues sale del cariño de sus padres con todas las alas de su libertad y alvedrio» se refuerza con la taxativa reprobación de que si eso no fuera así «ni sería a Dios agradable su obsequio, si quedassen en la voluntad aquellas plumas en que pudiesse bolar la inclinación azia el siglo». ${ }^{39}$ No sería agradable su sacrificio si «como la mujer de Loth bolviesse la cara al peligro que huye ${ }^{40}$ siendo en cambio que tiene que adoptar la actitud de su santo esposo: «agradecida a Dios, como este varón santo, ha de confessarle la mi[seri] cordia que recibe apartándola del corazón del peligro y conduciéndola a la seguridad de los claustros en donde toda ha de ser del esposo que la llama». ${ }^{41}$ De esta forma, abstraída de los cuidados del siglo, «ha de ser su conversación en los cielos y que empieza a difundirse en su linage el suave rocío de estas santas inspiraciones, acreditando la pureza de sus obras que es del cielo su vocación a los claustros»; de estos diálogos celestes y de este «santo comercio con las virtudes nacen como connaturales atributos aquellos consuelos en que suelen infundir Dios a las almas, comutando el Señor las delicias del mundo con las suavidades que incluye el estado religioso». ${ }^{42}$

Expuesto todo ello el predicador sólo considera oportuno recordar que a tal beneficio «ha de responder señora (...) su agradecimiento, zelando siempre el honor de su esposo con la práctica

36 Ibidem: f. 49r.

37 Ibidem: f. $55 \mathrm{v}$.

38 Ibidem: ff. 45r-45v.

39 Ibidem: f. $49 \mathrm{v}$.

40 Ibidem: f. $37 \mathrm{v}$.

41 Ibidem: f. 47v.

42 Idem

SCRIPTA, Revista internacional de literatura i cultura medieval i moderna, núm. 8 / desembre 2016 / pp. 314-337 ISSN: 2340-4841 · doi:10.7203/SCRIPTA.8.9302 


\section{Alejandro José López Ribao. Dominus qui incepit ipse perficiat: exhortaciones de fray Josep Mercader a las} monjas dominicas del monasterio de Montesión en Barcelona (1740-1745)

de las virtudes en que ha de vestir y ennoblecerse el alma» ${ }^{43}$ y aconsejar que contra más se ejercite en la práctica de estas virtudes «tanto más suave hallará al Señor de ellas, porque nunca el corazón humano dilata más affectuosas sus alas que corriendo el camino de los mandamientos divinos». ${ }^{44}$

En el caso de las pláticas para la ceremonia de la profesión las palabras introductorias no son unívocas. En algunas se retoma el circunloquio antes comentado en torno a la fórmula de la misericordia y se desarrolla gran parte del discurso a través del mismo motivo. Con ese objetivo se menciona, oportunamente al principio del texto, la expresión ya vista en el caso de las vesticiones «Pide la mi[seri]cordia de Dios después de aver conseguido la de estas señoras», explicándose en qué consiste esta misericordia «es la misericordia de Dios el premio grande que concede señora a los que siguen sus mandamientos, es la corona que ciñe las sienes de sus escogidos después que en este valle de lágrimas han consumado el curso de sus merecimientos», y recordándose dos ejemplos de misericordia como actitud vital y premio para el creyente:

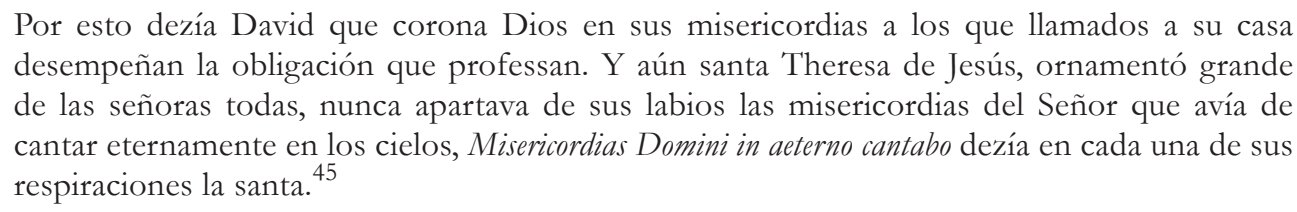

Gracias a esta sentencia sálmica, tan ligada iconográficamente a la santa de Ávila, es como su persona se hace presente en las pláticas, siendo las palabras laudatorias del autor «ornamento grande de las señoras todas», junto con el hecho de que es la única santa religiosa o monja no dominica de la que se hace mención, prueba de un aprecio especial hacia su persona.

El origen y discernimiento de la misericordia divina se sugiere a las almas mediante la vocación: «Se insinúa a las almas esta misericordia quando Dios, con su llamamiento, las aparta del peligro y con la luz que en sí llevan los divinos auxilios las conduce a la seguridad de un claustro religioso» y a dicha insinuación se debe el beneficio de ser llamadas al monasterio, en donde sus obras han de guiarse mediante la luz de las constituciones y «tomando la luz del buen exemplo que ha visto brillar en estas señoras religiosas». ${ }^{46}$ Éste es el camino oportuno que libra de la extravagancia, que planta sus raíces en el amor propio según el obispo de Hipona, y de la búsqueda de singularidad, polilla de la vida comunitaria para el fundador de la Cartuja: «por este camino andará segura, sin tropezar en los riesgos que trae consigo la extravagancia, porque ésta dize san Agustín suele tener sus raízes en el amor propio; y toda singularidad, dize san Bruno, es polilla de una comunidad religiosa». ${ }^{47}$

\footnotetext{
43 Ibidem: f. $53 \mathrm{v}$.

44 Ibidem: f. 38r.

45 Ibidem: f. 45r.

46 Idem

47 Ibidem: f. 45r.
} 

Alejandro José López Ribao. Dominus qui incepit ipse perficiat. exhortaciones de fray Josep Mercader a las
monjas dominicas del monasterio de Montesión en Barcelona (1740-1745)

En otras ocasiones el orador prefiere iniciar su discurso significando la especial importancia de aquella jornada y poniendo de relieve su figuración como renuncia del mundo y búsqueda de la vida en Cristo:

\begin{abstract}
Estamos pues señora en el día en que dexando al mundo acaba de cortar las esperanzas al mundo y a pesar del engaño en que suele la vanidad lisongear al appetito pisa oy su carrera con que ante animosa llamada de la estrella de mi santo patriarca y enseñada en sus claustros (...) se dedica todo a Jesucristo, prefiriendo la imortalidad de su esposo a la caducidad que dexa hallarse en el siglo. ${ }^{48}$
\end{abstract}

En algunas pláticas se cree oportuno indicar qué aporta la profesión a la vestición y para ello se recurre a la comentada frase de los sermones de san Bernardo: «y a los (ardores) que tuvo quando vistió el santo hábito añade oy la satisfacción de afrecerse toda a Jesucristo (...) que por esta razón dezía san Bernardo que la professión vincula lo que el amor concilia: amor conciliat professio maritat). ${ }^{49}$

Una vez más el recuerdo de la necesaria libertad a la hora de emitir, en este caso, la profesión religiosa ocupa un lugar importante en el discurso. Nadie indujo a la novicia a entrar en religión y nadie la debe inducir a profesar "porque la misma libertad con que entró en este exemplar monasterio ha tenido siempre para salir de sus claustros». ${ }^{50}$ Es Dios quien «con el respeto amoroso de hija, dexando a su discreción reconocer los caminos que alumbrava la voz de su mi[seri]cordia» la llamó en el día de su recepción y también quien la vuelve a llamar ahora:

\footnotetext{
Audi filia, et vide buelve Dios a llamarla deseando toda su atención a la voz del que ha de poseer sus aff[ec]tos y todas las potencias de su alma inclina aurem tuam por esto le dize el Señor mismo (...) olvide también las esperanzas que pudieran lisonjear su appetito porque entra a dominar su alvedrío el que la llama enamorado de su alma obliscere populum tuum et domum patris tui quia concupinit rex speciam tuam. ${ }^{51}$
}

Gracias al tiempo de noviciado la candidata ha podido juzgar con libre albedrío qué camino seguir. Demuestra en ese momento escoger el camino del monasterio, elección que una vez más se nos recuerda «no sería agradable a Dios (...) si faltasse la libertad en que mira Dios lo más precioso de sus aras, ni sería racional su obsequio si cayesse de su corazón una pluma que pudiesse estorvarle bolar ligera y con plena libertad a su esposo». ${ }^{52}$

\footnotetext{
48 Ibidem: f. 31 r.

49 Ibidem: f. 33 r.

50 Ibidem: f. $31 \mathrm{v}$.

51 Ibidem: f. 35 r.

52 Ibidem: ff. $35 \mathrm{r}-35 \mathrm{v}$.
} 

Alejandro José López Ribao. Dominus qui incepit ipse perficiat. exhortaciones de fray Josep Mercader a las
monjas dominicas del monasterio de Montesión en Barcelona (1740-1745)

El año de noviciado se muestra como el tiempo adecuado para llevar a cabo el discernimiento entre dos caminos: «Ha podido ver en este año los caminos que dexa en el siglo y los que ha de caminar de religiosa (...) ha podido reconocer los caminos de la valle de este mundo y los de Montesión en donde ha ser su morada». Unos son cortos y vidriosos y los otros «illuminados con la luz del desengaño» guían al cielo. En unos el corazón se encuentra inquieto sin hallar el bien permanente que satisfaga la voluntad humana, mientras que en los otros la voluntad humana encuentra el bien supremo «que es el depósito de todos los thesoros»; en definitiva recuerda «que esto decía el Espíritu Santo a su esposa, que la llevaría por los caminos de la equidad y por aquellas sendas en donde se halla sin tropiezo alguno la virtud Ducam te per semitas aequitatis, quas cum ingressus fueris, non arcatabuntur gressus tuì. ${ }^{53}$

Siguiendo con los binomios contrapuestos se traza el tema de la diferencia entre el amor divino y el amor humano a través de su analogía con el fuego:

\begin{abstract}
Con mucha razón se compara el amor al fuego porque assí como éste no cessa de estenderse y dilatar su llama mientras halla materia que sustente su natural actividad assí el amor no tiene sosiego, no conoce en sí mismo descanso sino que busca con una generosa inquietud nuevos assumptos (...). De este principio nace aquella gran diferencia que ay entre el amor div[in]o y humano. Éste, aunque tiene su impulso de la perf[ecci]ón y el bien, se debilita fácilmente y desvanece porque como sigue a un objeto variable y limitado apura la razón de aquel bien que aprendió apetecible. Pero el amor divino, como mira a Dios en cuya bondad no cabe mudanza ni cadencia alguna de sus i[n]mutables perfecciones, crece y se aumenta a proporción de lo que se exercita, hallando siempre nuevas razones y motivos que a la voluntad para amarle. ${ }^{54}$
\end{abstract}

Gracias al versículo 13 del salmo 65 y al comentario del mismo que hace Casiodoro se intenta perfeccionar la idea de la profesión como holocausto agradable a Dios, como la forma de entrar en su morada, el real monasterio de Montesión en este caso, y cumplir sus votos inflamada por el mencionado fuego de la caridad divina:

\begin{abstract}
Entraré Señor, dize en boca de David una professa, como holocausto a tu casa y allí daré cabal cumplimiento a mis votos y entera satisfacción a mis deseos: introibo in domum tuam in holocaustis, reddam tibi vota mea quae distinxerunt labia mea. Se contenta en espíritu fervoroso de entrar a la casa de Dios como sacrificio (...), entra poseída de la charidad como holocausto la que enciende todos los aff[ect] os en honor y culto de la Majestad que adora. ${ }^{55}$
\end{abstract}

En el apartado anterior apuntábamos que algunos temas e incluso párrafos de las pláticas fueron

53 Ibidem: f. $31 \mathrm{v}$.

54 Ibidem: f. 31 r.

55 Ibidem: f. $35 \mathrm{v}$.

SCRIPTA, Revista internacional de literatura i cultura medieval i moderna, núm. 8 / desembre 2016 / pp. 314-337 ISSN: 2340-4841 · doi:10.7203/SCRIPTA.8.9302 
Alejandro José López Ribao. Dominus qui incepit ipse perficiat. exhortaciones de fray Josep Mercader a las monjas dominicas del monasterio de Montesión en Barcelona (1740-1745)

tomados de la obra de fray J. Medina (1710). Debido a que pueden ser consultados en dicha obra, ya que no se trata de un texto inédito como el que estamos comentando en nuestro artículo, y además no pueden ser considerados como pensamiento original de J. Mercader sólo los enumeraremos e indicaremos su referencia bibliográfica. Dichos argumentos se concentran sobre todo en la primera plática para la profesión que ha llegado hasta nosotros, pronunciada el 20 de marzo de 1740 y retomada cuatro años más tarde el 20 de abril de 1744. En ella la sentencia del cardenal Hugo de San Caro «Veni per mundi contemptum veni per ardorem dilectionis» sirve para articular la afirmación de que son dos los caminos que llevan al esposo divino: el desprecio del mundo y por el ardor de la caridad. ${ }^{56}$ De igual manera el episodio en que el profeta Isaías describe ver hombres que, en forma de nubes, volaban a las alturas se emplea como introducción para la interpretación de fray Luis de Granada que identifica las nubes con las almas piadosas consagradas a Dios, las cuales sólo aspiran, ensalzando su vuelo desde esta tierra, a la beatitud celeste. ${ }^{57}$ Aunque en este caso la mención a fray Luis de Granada se deba a la transcripción del argumento tal y como viene consignado en el Prontuario no es extraña en los oradores blanquinegros del momento, dada la gran popularidad del autor y su estimable y repetido valor como modelo de predicación. ${ }^{58}$ Por último, una sentencia de san Bernardino de Siena sirve para desarrollar el tema de la necesidad de «condimentar» todas las buenas obras con sal tal y como pidió Dios en el Levítico que se hiciera con los sacrificios a Él destinados (Lev 2, 13): «Ubi amor defuerit nibil vales quidquid agitur, omnia valent qua cum amore aguntun». La sal de aquellos antiguos sacrificios se identifica ahora con el amor, con la caridad necesaria en toda buena obra para que se constituya en tal y con la exhortación a que sea la caridad la guía y condimento querido por Dios en toda oblación religiosa. ${ }^{59}$

Argumento obligado en una composición del género es la transitoriedad del mundo, la inestabilidad de las cosas terrenas que lleva a la religiosa a buscar su felicidad en la inmutabilidad de Dios. Aunque la idea la podamos encontrar en el citado prontuario, siguiendo al resto de temas antes mencionados, en este caso la forma de tratarla no sigue el discurso del franciscano sino que se nos ofrece una pequeña composición retórico en torno al sol y al giro de su esfera:

\footnotetext{
Transeunt universa sub sole, dezía a la luz del desengaño el Ecclesiastés. En el teatro de este mundo ya ha visto señora que es una continua revolución la de sus partes, pues no se halla bien permanente en que pueda sosegar el corazón humano. Como el mismo sol en el giro de su esfera andan los mortales en la rueda de su fortuna todos los meses muda el sol de casa y conforme la variedad de los signos en que entra se mudan las leyes del estado que professa.
}

56 Ibidem: f. 39r y J. Medina (1705: 414-415).

57 Ibidem: f. 39v y p. 414.

58 Consultar al respecto el artículo de (Esponera 2005: 257-278). Sobre el «éxito editorial” de fray Luis de Granada en Cataluña consular Blanco (2012: 147-177).

59 BUB, ms. 747, ff. 39v-40r y pp. 414-416.

SCRIPTA, Revista internacional de literatura i cultura medieval i moderna, núm. 8 / desembre 2016 / pp. 314-337 ISSN: 2340-4841 · doi:10.7203/SCRIPTA.8.9302 


\title{
Alejandro José López Ribao. Dominus qui incepit ipse perficiat. exhortaciones de fray Josep Mercader a las monjas dominicas del monasterio de Montesión en Barcelona (1740-1745)
}

Entra el sol en el signo de Sagitario y armado de sus saetas exercita el officio de guerrero. Passa el sol al signo de Aquario y con lágrimas del cielo se ostenta penitente. Llega el sol al signo de libra y se haze juez de las discordias de los elementos. Con la misma instabilidad corren los hijos de Eva la carrera de esta vida. ${ }^{60}$

Más allá de estos temas comunes en varias pláticas encontramos algunos específicos que se justifican por diversas razones. Una de ellas es la necesaria mención al santo del día (san Andrés apóstol). El hecho da pie para exhortar a sor María Antonia Güell a conservar en la memoria esa jornada especial en que se retira del mundo y a recordar igualmente las motivaciones que la movieron a ello:

\begin{abstract}
Pues esta consider[aci]ón que pudo moverla a retirarse del siglo ha de quedar permanente en su memoria, ni ha de quedarle en olvido la circunstancia del día en que viste el santo hábito, porque a más de illustrarle las glorias de tan insigne apóstol es más claro en su memoria porque en este día (...) salió a la luz del mundo, y es conveniente quedar impresso en su memoria el mismo día en que renace a la luz del cielo en cuya eternidad etcétera. ${ }^{61}$
\end{abstract}

En una sola ocasión se nos pondera como bien de la vida monástica la paz que infunde en el alma, motivada por el abandono del mundo y el gozar de las suavidades del estado religiosos:

Como compañero de estos consuelo[s] salta a la vista la paz que ofrece oy Cristo en su Evangelio, dexando en el alma inexplicable el gozo que sintieron los discípulos de oír a Cristo resuscitado. Ésta es la paz que dexa en el alma el testimonio de una conciencia buena y ésta es la joya que con más cuydado han de guardar con el santo hábito que han de vestirse. ${ }^{62}$

Un caso curioso es el que encontramos en la plática para la recepción de sor María Ignacia Guzmán. En ella, aprovechando la supuesta relación familiar con el patriarca fundador, se exhorta a meditar sobre el ejemplo del mismo y actuar en consonancia y honor con tan gran apellido:

\footnotetext{
Ni ha de quedarse en olvido la circunstancia del apellido que lleva porque siendo Guzmán de nacimiento han de imprimirse en su memoria los hechos maravillosos con que mi santo patriarca ennobleció el trono de los Guzmanes, enriqueciendo las ramas de este. (...) Vestirá con el hábito una obligación muy particular satisfazer atenta a su apellido, porque sería más notable la mancha si dexasse de ser tan Guzmán. ${ }^{63}$
}

\footnotetext{
60 BUB, ms. 747, ff. 39r-39v.

61 BUB, ms. 747, f. 54 r.

62 Ibidem: f. 56r.

63 Ibidem: f. 49v.
} 


\section{Alejandro José López Ribao. Dominus qui incepit ipse perficiat. exhortaciones de fray Josep Mercader a las} monjas dominicas del monasterio de Montesión en Barcelona (1740-1745)

Por último, entre los exempla de mujeres santas ofrecidos a las profesas, se distingue el dedicado a santa Cecilia que el prior de Santa Catalina creyó oportuno traer a la memoria por el oficio de organista de la nueva monja profesa en Montesión. De esta manera sentencia que «Ceñida pues a esta observancia de las leyes que professa y al exercicio del órgano en que la religión la destina logrará la quietud interior de su alma, viviendo en gracia con su esposo» ${ }^{64} \mathrm{y}$ se permite recordar que debe tener siempre presente el ejemplo de la mártir romana:

\footnotetext{
Tiene un noble exemplar en santa Cecilia que, componiendo sus affectos al tono del órgano que tañía, cantava a Dios las con el mismo espíritu en que dava a Dios sus affectos fervorosos. Desde el registro que tocavan sus manos registrava la bienaventuranza que deseava en los cielos y calentando sus affectos con el mismo movimiento de las teclas dava a Dios su corazón armonioso con el músico instrumento a que dava las manos. Fortalesía a la santa el sagrado Evangelio que llenava siempre en su pecho esta esposa enamorada de Jesucristo: evangelium Christi gerebat in pectore quiere dezir con estas palabras el rezo que animava su pecho los mandamientos de la ley y los santos consejos que están expressados en el Evangelio. ${ }^{65}$
}

Con el objetivo de concluir este apartado nos gustaría detenernos en los ejemplos femeninos que se presentaron a las religiosas en el día de su vestición y profesión; ver así cómo la imitación de santas mujeres es valorada por el predicador y como tal viene mostrada a otras mujeres que se inician en el camino de la perfección. En primer lugar llama la atención que J. Mercader no utilizara para ese fin la figura de la Virgen María, siendo que sólo la cita en una ocasión aunque con encomiables halagos: «que en el Montesión subió María Santísima, que es el exemplar más $\mathrm{i}[\mathrm{n}]$ mediato que presenta a su vista este templo». ${ }^{66}$ Más nos sorprende si apreciamos que una de las profesiones se fecha el 8 de diciembre, fiesta, en aquella época, de la Concepción de María (totum duplex), no aprovechando en aquella ocasión el fraile blanquinegro la coyuntura para dedicar su atención a ella.

Las menciones a las santas mártires Águeda y Cecilia han sido tratadas anteriormente y de igual forma hemos constatado la breve pero vigorosa referencia a santa Teresa de Jesús.

Por último, queremos poner de relieve que la santa más presente en las pláticas es santa Catalina de Siena, siendo ella la única que goza de una especial atención retórica. Se presentan a las religiosas de Montesión tres episodios de su biografía. El más curioso de ellos es el que la relaciona con santa Inés de Montepulciano bajo las circunstancias antes indicadas. En esa ocasión se exhorta a las religiosas a observar el jardín de santidad que ofrece su religión y reparar en su figura:

64 Ibidem: f. 45r.

65 Ibidem: ff. $45 \mathrm{r}-45 \mathrm{v}$.

66 Ibidem: f. 49v. 


\title{
Alejandro José López Ribao. Dominus qui incepit ipse perficiat. exhortaciones de fray Josep Mercader a las monjas dominicas del monasterio de Montesión en Barcelona (1740-1745)
}

Tiene a su vista tantas santas como han florecido en este vergel hermoso, llenando de suave fragancia los altares que illustran el templo de la gloria. Pero la que entre todas ha de servirle señaladamente de exemplo es santa Inés de Montepulciano en cuyo felicíssimo día professa la misma religión y santas leyes que professó la santa.

Para continuar relatando el encuentro de santa Catalina con el cuerpo de santa Inés y la honda impresión que causó en ella el milagro que en esa ocasión se le concedió:

\begin{abstract}
Ya sabe señora que de santa Inés de Monte Pulciano es copia una santa Catharina de Sena. Permítame la gran dignación de q[uan]tos sufren la impaciencia de oírme acordarle el caso que sucedió a santa Catharina cuando quiso visitar el cuerpo de santa Inés de Monte Pulciano. Levanta ésta el pie desde la urna en que jacía su cadáver y dándole a besar a santa Catharina le dio en esta demonstración obsequiosa un exemplo milagroso de la virtud que jamás pudo borrar de su alma animada con este exemplo, que aún desde el cuerpo difunto infundió vitalidad a la de Sena, se esmeró toda en copiarla las más bellas perf[ecci]ones. ${ }^{67}$
\end{abstract}

El siguiente episodio concerniente a la doctora de la Iglesia se sitúa en su infancia, cuando Catalina, antes de tomar el tan deseado hábito, expresó a sus padres lo que su belleza había significado para ella: «Por esto Santa Catalina de Sena, en aquel colloquio (...) que tuvo con sus padres antes de vestir el santo hábito, les dixo (...) que la muerte que acaban de ver (...) en su hermosura fue para sí primeramente dolor, passó luego a desengaño y últimamente la sirvió (...) de fruto». ${ }^{68}$

El último episodio que se nos narra reproduce el bello soliloquio que tuvo la santa una vez vestido el hábito. Es interesante ver como nuestro orador «tergiversa» o simplemente «sacrifica» a la retórica la veracidad del suceso, ya que éste se consigna en todas las biografías tras la toma de hábito y no tras la profesión como él menciona. Además en el caso de santa Catalina, al no haber sido monja de clausura, nunca se dio dicha ceremonia de profesión. Sin embargo, las atractivas y ejemplificantes palabras de la santa le sirven a J. Mercader para cerrar de forma magistral su discurso:

\footnotetext{
Y no escusaré trasladar de la historia las mismas palabras en que respirava el fervor de santa Catalina luego que se vio professa de nuestro sagrado hábito porque son dignas de estamparse en su memoria y más dignas de nota por averlas dicho la santa en la misma función en que usted se halla: ya Cathalina (...) veamos aora como desempeñas tan alto beneficio como cumples la oblig[ac]ión de tu estado, como acreditas entre los hu[mi]ldes rendimientos de esclava los ardores affectuosos de esposa, como aprovechas los exemplos de esta casa y como en fin muestras ser hija digna de tan illustre Padre. Son palabras de la santa. ${ }^{69}$
}

67 Idem

68 Ibidem: f. 32r.

69 Ibidem: f. 36r.

SCRIPTA, Revista internacional de literatura i cultura medieval i moderna, núm. 8 / desembre 2016 / pp. 314-337 ISSN: 2340-4841 · doi:10.7203/SCRIPTA.8.9302 
Alejandro José López Ribao. Dominus qui incepit ipse perficiat. exhortaciones de fray Josep Mercader a las monjas dominicas del monasterio de Montesión en Barcelona (1740-1745)

\section{Conclusión}

Fray Josep Mercader se perfila como uno de los dominicos más destacados del siglo XVIII catalán. Esta afirmación se fundamenta en los puestos de responsabilidad que detentó, en las instituciones intelectuales de las que formó parte y en el amplio volumen de sermones manuscritos, fruto de una intensa actividad como orador sagrado, que conservamos. Su obra, poco conocida aún, nos puede ofrecer muchos matices sobre el autor y su contexto, siendo este el caso de las breves exhortaciones que hemos analizado. En ellas se puede contemplar, desde una perspectiva especialmente afectiva y efectiva, cuál era el discurso de un reputado eclesiástico a las monjas de clausura de su orden en las ceremonias de su recepción y profesión. Es interesante apreciar como conjuga en su oratoria fuentes bíblicas (ostensiblemente más numerosas del Antiguo Testamento que del Nuevo Testamento), teológicas (con la significativa excepción de santo Tomás de Aquino), litúrgicas, «manualísticas» y hagiográficas para componer unos textos de alto contenido religioso sin renunciar a una retórica brillante y metafórica. Las exhortaciones que hemos trabajado nos muestran un discurso religioso y teológico específico por su contexto, por su fuerza y por sus características formales. Sería interesante compararlas con otras pláticas dedicadas a monjas pero insertas en otras coordenadas, de esta manera podríamos evaluar cuál era la especificidad del mensaje y cuál la voluntad de transmisión de una específica tradición dominicana que fray Josep Mercader quiso compartir y grabar en la mente de aquellas monjas de Montesión.

Dominus qui incepit ipse perficiat 
Alejandro José López Ribao. Dominus qui incepit ipse perficiat. exhortaciones de fray Josep Mercader a las monjas dominicas del monasterio de Montesión en Barcelona (1740-1745)

\section{Bibliografía}

Aguilar, F. (1989) «Predicación y mentalidad popular en la Andalucía del siglo XVIII», en Buxó M.J. / Rodríguez S. (eds.) La religiosidad popular: vol. II, Barcelona, Anthropos, pp. 57-71.

Atienza, A. (2013) «El mundo de las monjas y de los claustros femeninos en la edad moderna», en Serrano E. (ed.) De la tierra al cielo. Lineas recientes de investigación en Historia Moderna, Zaragoza, Institución «Fernando el Católico» (C.S.I.C.), pp. 89-108.

Benet de Nursia, (1997) Regla per als monjos, Barcelona, Publicacions de l'Abadia de Montserrat.

Blanco, C. (2012) «La proyección editorial de los dominicos en la Cataluña Moderna», en Alabrús R.M. (ed.), La memoria escrita de los dominicos, San Cugat, Arpegio, pp. 147-177.

Bravo, M.D. (2001) «Un sermón de profesión de monjas del siglo XVII: la retórica de la perfección», C.M.H.L.B. Caravelle, 76-77, pp. 391-399.

Breviarium Sacri Ordinis Praedicatorum auctoritate apostolica approbatum et reverendissimi P. F. Thomae Ripoll ejusdem Ordinis Generalis Magistri Jussu editum, Typis Hyeronimi Mainardi apud theatrum Capranicense, Roma, 1738.

Campabadal, M. (2012) «Mercader, Joseph», en Molas P. / Durán E. / Massot J. (eds.) Diccionari biogräfic de l'Acadèmia de Bones Lletres, Barcelona, Fundació Noguera, pp. 256-257.

Clarae-Vallensis, B. (1839). Opera Omnia, vol. 1, París, Gaume Fratres.

Cárdenas, F.J. (2015) «Un acercamiento a la alegoría en la profesión de monjas novohispanas», Revista destiempos, 14, pp. 34-46.

Collell, A. (1965) Escritores dominicos del Principado de Cataluña, Barcelona, Ediciones de la Ponencia de Cultura de la Diputación de Barcelona.

Egido, T. (1996) «Religión», en Aguilar F. (ed.) Historia literaria de España en el siglo XVIII, Madrid, Trotta, pp. 739-814.

Esponera, A. (1997) «Sobre la predicación en la Valencia del último cuarto del siglo XVIII», Anales Valentinos, 46, 351-378.

. (2005) «Presencia de Fray Luis de Granada en algunos dominicos valencianos del siglo XVIII»Comunio, 38, pp. 257-278.

Gómez, V.T. (2011) Santo Domingo de Guzmán. Escritos de sus contemporáneos, Madrid, Edibesa.

Gómez, S. (2011) «De rejas adentro: monjas y religiosas en la España Moderna. Una historia de diferencias en la igualdad», Revista de Historia Moderna, 29, pp. 205-228.

Grau, S. (2012) «Una breve disertación sobre los valdenses de Josep Mercader (1764)», Hispania Sacra, 129, pp. 279-307.

Guglielmotti, A. (1860) Catalogo dei bibliotecari, cattedratici e teologi del Collegio Casanatense nel convento della Minerva dell'Ordine de' Predicatori in Roma, Roma, Tipografia delle belle arti. 
Alejandro José López Ribao. Dominus qui incepit ipse perficiat. exhortaciones de fray Josep Mercader a las monjas dominicas del monasterio de Montesión en Barcelona (1740-1745)

Hernández, M.S. (2002) «La celda del convento, una habitación propia. La vivencia de la clausura en la comunidad de dominicas de Montesión», DUODA Revista d'Estudis Feministes, 22, pp. 19-40.

Medina, J. (1705) Prontuorio de superiores regulares para alentar, exortar y corregir a sus súbditos para la mayor observancia de la vida monástica y religiosa y de eclesiásticos conductores de almas por la carrera de la virtudy perfección, Barcelona, Jayme Surià impressor.

Mercader, J. (1756) Oración fúnebre que en las exequias... a la memoria de su presidente el... Conde de Perelada, dixo ... fr. Joseph Mercader, Barcelona, en la imprenta de Francisco Surià.

Mestre, A. (1979) «La reforma de la predicación en el siglo XVIII (A propósito de un Tratado de Bolifón)», Anales Valentinos, 2, pp. 88-119.

(1997) «Los programas de reforma de la Iglesia en los ilustrados valencianos», Anales Valentinos, 46, pp. 245-263.

Miquel, F. (1958) Inventario general de manuscritos de la Biblioteca Universitaria de Barcelona. Madrid, Direcciones generales de enseñanza universitaria y de archivos y bibliotecas, Servicio de publicaciones de la Junta Técnica.

Missale sacri ordinis praedicatorum. Auctoritate Apostolica approbatum Rmi. P.F. Thomae Ripoll eiusdem ordinis generalis magistri iussu editum, Typis Hyeronimi Mainardi apud theatrum Capranicense, Roma, 1726.

Morand, F. (2004) «El papel de las monjas en la sociedad española del setecientos», Cuadernos de Historia Moderna, 29, pp. 45-64.

Regla de San Agustiny Constituciones que profesan las religiosas del Patriarca Santo Domingo, Agapito Manteli, Vitoria, 1826.

Regola e costituzioni delle suore di san Domenico reviste e ristampate d'ordine del reverendissimo padre Generale fra Antonino Cloche, Francesco Gonzaga nella Stamperia del Tinassi, Roma, 1709.

Regula S. Augustini et Constitutiones ff. ordinis praedicatorum nunc recenter reimpressae. Jussus reverendiss. patris Antonini Cloche, ejusdem Ordinis Magistri Generlis, Typis Nicolai Angeli Tinassii, Roma, 1690.

Ricchiedei, P. (1710) Constitutioni delle suore dell'Ordine di San Domenico dichiarate et esposte dal padre maestro fra' Paolo Ricchiedei del medesimo ordine per maggior loro istruttione e frutto spirituale, Génova, Antonio Casamara. 